\title{
Distinguishing Galactomyces citri-aurantii from G. geotrichum and Characterizing Population Structure of the Two Postharvest Sour Rot Pathogens of Fruit Crops in California
}

\author{
A. H. McKay, H. Förster, and J. E. Adaskaveg
}

Department of Plant Pathology and Microbiology, University of California, Riverside 92521.

Current address of A. H. McKay: The New Zealand Institute for Plant \& Food Research Ltd., Mount Albert Research Centre, Private Bag 92169, Auckland 1142, New Zealand.

Accepted for publication 1 February 2012.

\begin{abstract}
McKay, A. H., Förster, H., and Adaskaveg, J. E. 2012. Distinguishing Galactomyces citri-aurantii from G. geotrichum and characterizing population structure of the two postharvest sour rot pathogens of fruit crops in California. Phytopathology 102:528-538.

A growth assay in lemon juice and polymerase chain reaction amplifications using newly designed species-specific primers from endopolygalacturonase and $\beta$-tubulin genes rapidly differentiated isolates of the morphologically similar fruit sour rot pathogens Galactomyces citriaurantii and G. geotrichum. Isolates of both species were collected from agricultural soils and decaying fruit at locations within and outside California, including worldwide locations, and were used in population genetic studies based on amplified fragment length polymorphic (AFLP) DNA markers. For all four geographically defined subpopulations (three counties of California and locations outside California) among 97 isolates of G. citri-aurantii and for the two subpopulations (origin within or outside California) among 35 isolates of G. geotrichum, the proportion of polymorphic loci and haplotypic diversity was high. In total, 82 unique haplotypes were identified for G. citri-aurantii for the four subpopulations and, of these, 80 haplotypes were unique among subpopulations. For G. geotrichum, 25 unique haplotypes were identified among the two

subpopulations and no haplotype was shared. Indices of genetic differences $\left(F_{S T}\right)$ between subpopulations within each species were all low (e.g., 0.038 for $G$. geotrichum and 0.085 to 0.226 for $G$. citriaurantii), indicating a low level of genetic differentiation. Following clone correction, mating type segregation ratios for G. citri-aurantii did not significantly $(P>0.1)$ deviate from a 1:1 ratio for all four subpopulations or the entire population. Tests of the index of association $\left(\mathrm{I}_{\mathrm{A}}\right)$ and parsimony tree-length permutation tests (PTLPT) supported a random mating structure for clone-corrected data for the Kern, Tulare, and Ventura County subpopulations and the null hypothesis of random mating could not be rejected. Additionally, PTLPT also supported random mating for the "outside of California" population. For G. geotrichum, random mating was only tested using $\mathrm{I}_{\mathrm{A}}$ and PTLPT and the null hypothesis of random mating was not rejected $(P>0.05)$ using clonecorrected data. Further evidence that sexual recombination likely occurs in both species of Galactomyces was the lack of grouping consistency in the unweighted pair-group method with arithmetic mean clustering of AFLP data. A high confidence based on bootstrap values was obtained for only a few of the nodes in each of the two trees. A mixed reproduction system with an out-crossing sexual mating system and a prolific asexual phase is proposed for both species.
\end{abstract}

Galactomyces citri-aurantii E. E. Butler, the causal pathogen of sour rot of citrus fruit, is a haploid, heterothallic ascomycete fungus that was first reported on lemon fruit in California in 1917 (28). The pathogen has also been recognized as Geotrichum candidum var. citri-aurantii (Ferraris) Cif. \& F. Cif., the variety name denoting the ability to infect citrus fruit and grow at a low $\mathrm{pH}(<2.7)(7,8,11)$. Galactomyces citri-aurantii is morphologically very similar to G. geotrichum (E. E. Butler \& L. J. Petersen) Redhead \& Malloch (anamorph Geotrichum candidum Link.), the pathogen that causes sour rot of stone fruit, melon, tomato, and other fruit $(1,33)$. In 1972, the sexual stage of $G$. candidum was observed for the first time in crosses between isolates from Puerto Rico, and the teleomorph Endomyces geotrichum E. E. Butler \& L. J. Peterson was described (10). In 1988, Butler et al. (9) also described the teleomorph of the citrus pathogen and separated the two pathogens as species. Both species of Galactomyces were described as heterothallic with two mating types $(9,10)$. Due to sexual incompatibility of the citrus

Corresponding author: J. E. Adaskaveg; E-mail address: jim.adaskaveg@ucr.edu

*The $\boldsymbol{e}$-Xtra logo stands for "electronic extra" and indicates that Figure 3 appears in color online.

http://dx.doi.org/10.1094/PHYTO-05-11-0156

(C) 2012 The American Phytopathological Society pathogen with isolates of G. geotrichum from non-citrus hosts, the two fungi were placed into separate biological species. Researchers in Japan, however, were unable to detect the sexual phase of G. citri-aurantii and, thus, have contended that the two species are races of the same species, Geotrichum candidum (31). Galactomyces citri-aurantii and G. geotrichum are widely distributed in agricultural soils worldwide but the citrus pathogen is thought to be geographically and biologically confined to the citrus environment (9).

Due to cultural and morphological similarities of G. citriaurantii and G. geotrichum, differentiation of the two species can be difficult. Various biochemical and physiological characteristics have been used to facilitate species identification. For example, differential pathogenicity to citrus fruit has been used in some studies (32). Secretion of extracellular endo-polygalacturonases that aid in the rapid breakdown of infected tissues $(14,33)$ was found to be higher in the citrus pathogen (24). The two species also exhibit a different growth pattern in citrus juices $(9,33)$. Additionally, genetic variability was detected in the internal transcribed spacer region of ribosomal DNA (23). Based on these reports, it is apparent that more specific methods are needed to separate the two species.

Although sour rot causes substantial economic losses in agriculture worldwide $(5,16,29)$ and both fungal pathogens are commonly found in soils, little is known about the population genetic 
structure of G. citri-aurantii and G. geotrichum or the extent to which sexual reproduction contributes to the epidemiology and diversity of these fungi. This information could have important implications when developing strategies to manage these diseases. For example, pathogenic fungi that have a sexual stage and display outcrossing may better respond to selection pressures such as the introduction of new fungicide treatments $(21,22)$. As for many ascomycete fungi, the sexual stage of G. citri-aurantii is not commonly observed in soils or in infected fruit. The abundantly produced asexual arthroconidia are considered to be the main inoculum (11) and the single-spored asci are small (8 to 12 by 7 to $9 \mu \mathrm{m}$ in diameter) and difficult to detect $(9,10)$. Thus, the extent of sexual reproduction in the fungal population may not be evident due to the predominance of asexual spores. In recent years, population genetic methods have been used increasingly to deduce information on population structure, sexual reproduction, and gene flow from mating type markers, as well as molecular data such as random amplified polymorphic DNA, amplified fragment length polymorphisms (AFLPs), and microsatellite markers $(4,13,26,36,39)$.

One method used to better understand the reproductive lifestyle of a fungal species is by determining the distribution of mating types within a population. Thus, for a randomly mating species, the distribution will be in roughly equal proportions (22). Another method is to examine genetic variability in natural populations through multilocus genotypic analysis and develop deductions on the life history of the species. For example, in a sexually reproducing population with random mating (panmixis), there will be little association between alleles at one locus with those of another locus unless they are linked, and multilocus genotypes will be highly variable when comparing individuals of the same species (22). In contrast, in an asexually or clonally reproducing fungus, alleles at different loci are strongly associated and the same multilocus genotype may be commonly recovered from different individuals within a population (3). A combination strategy of heterothallic mating with a definite asexual phase has been described as the most common fungal lifestyle (36).

The first objective of our research was to develop identification methods based on growth and molecular characteristics that would enable species distinction when analyzing large populations of the two Galactomyces spp. collected from fruit and soils of diverse environments. Another objective of our research was to determine by multilocus genetic analysis whether sexual reproduction of $G$. citri-aurantii and $G$. geotrichum that has been observed in the laboratory is also occurring in the field.

\section{MATERIALS AND METHODS}

Isolates of $\boldsymbol{G}$. citri-aurantii and $\boldsymbol{G}$. geotrichum. In total, 97 isolates of $G$. citri-aurantii and 35 isolates of G. geotrichum were used in the study. Isolates of G. citri-aurantii were recovered from symptomatic citrus fruit collected from packinghouses as well as from soils in commercial citrus groves and some noncitrus locations in Kern, Tulare, and Ventura Counties, CA, between 2006 and 2009 (Table 1). Isolates of G. geotrichum were obtained from soil in citrus or nectarine orchards or from peach fruit in packinghouses in California. For all isolates collected, information on the geographic origin was recorded. In all, 6 isolates of $G$. citri-aurantii and 14 isolates of G. geotrichum of worldwide origin were obtained from the collection of Dr. E. E. Butler, University of California, Davis.

Isolations from symptomatic fruit were made by excising a small section of fruit tissue from a subepidermal area at the margin of a sour rot lesion and placing it onto potato dextrose agar (PDA) (Difco Laboratories, Detroit) amended with fludioxonil at $1.0 \mu \mathrm{g} / \mathrm{ml}$ (Scholar 50WP; Syngenta Crop Protection) and novobiocin at $0.5 \mu \mathrm{g} / \mathrm{ml}$ (Sigma-Aldrich, St. Louis). Soil samples were collected 5 to $10 \mathrm{~cm}$ below the soil surface. Each composite sample consisted of 10 soil cores that were collected around the drip line from each of 5 to 10 trees/orchard. An aliquot of $3 \mathrm{~g}$ of soil was placed into 100-ml Erlenmeyer flasks containing $25 \mathrm{ml}$ of sterile water and was shaken at $150 \mathrm{rpm}$ on an orbital shaker for $2 \mathrm{~h}$. Aliquots of $1 \mathrm{ml}$ were added to sterile tubes containing $25 \mathrm{ml}$ of autoclaved lemon juice and incubated on a shaker at $200 \mathrm{rpm}$ for $48 \mathrm{~h}$ at $24^{\circ} \mathrm{C}$. From this mixture, $50 \mu \mathrm{l}$ was spread onto PDA amended with fludioxonil and novobiocin using a spiral plater (Autoplate 4000; Spiral Biotech, Norwood, MA) set at the exponential deposition mode. After 48 to $72 \mathrm{~h}$, colonies resembling Galactomyces spp. were excised and transferred to PDA for subsequent single-spore isolation. Species identification of each isolate was done using a lemon juice incubation test and by polymerase chain reaction (PCR) with newly designed speciesspecific primers as described below.

Growth characteristics of Galactomyces spp. in lemon juice. The assay was done using a modification of a previously published protocol (33). Conidial suspensions $\left(1 \times 10^{4}\right.$ conidia $\left./ \mathrm{ml}\right)$ of single-spore isolates were prepared in freshly pressed, autoclaved lemon juice ( $\mathrm{pH} 2.2$; undiluted or diluted 1:1 with sterile water), and $1 \mathrm{ml}$ of each suspension was pipetted into a 2-ml microcentrifuge tube and incubated on an orbital shaker at $150 \mathrm{rpm}$ for $48 \mathrm{~h}$. Aliquots of the cultures were then examined microscopically at $\times 200$ magnification. Cultures with elongated cells that fragmented into numerous conidia and with no mycelial clusters present were putatively considered to be $G$. citri-aurantii pending further evaluation by species-specific PCR (see below). Cultures with clusters of mycelial colonies present and with only a few individual conidia were putatively considered to be $G$. geotrichum. Each isolate was evaluated in two separate experiments.

DNA extraction. DNA was extracted using a modified protocol for the FastDNA Spin kit for soil (MP Biomedicals, Solon, OH) as follows. Hyphal and conidial tissue $\left(\approx 10 \mathrm{~mm}^{3}\right)$ was scraped from PDA cultures and placed into a $1.5-\mathrm{ml}$ screw-cap microcentrifuge tube containing six stainless steel beads $2.3 \mathrm{~mm}$ in diameter (BioSpec Products, Inc., Bartlesville, OK) and $100 \mu \mathrm{l}$ of $10 \mathrm{mM}$ Tris-HCl, $\mathrm{pH}$ 8. Samples were homogenized twice for $20 \mathrm{~s}$ each using a FastPrep-24 tissue homogenizer (MP Biomedicals) at $6.0 \mathrm{~m} / \mathrm{s}$. An additional $500 \mu \mathrm{l}$ of $10 \mathrm{mM}$ Tris- $\mathrm{HCl}, \mathrm{pH} 8$, and $85 \mu \mathrm{l}$ of MT buffer (MP Biomedicals) were added. The tubes were vortexed for $5 \mathrm{~s}$ and then centrifuged at maximum speed for $30 \mathrm{~s}$. The supernatant was transferred to $1.5-\mathrm{ml}$ snap-cap microcentrifuge tubes and $110 \mu \mathrm{l}$ of $7.5 \mathrm{M}$ ammonium acetate was added. Tubes were inverted 10 times and centrifuged at maximum speed for $5 \mathrm{~min}$. The supernatant was removed and placed into a new snap-cap microcentrifuge tube containing $300 \mu \mathrm{l}$ of Binding Matrix (MP Biomedicals). Tubes were placed on a platform shaker for $5 \mathrm{~min}$ at $150 \mathrm{rpm}$ and centrifuged for $30 \mathrm{~s}$, and the pellet was washed twice with $300 \mu \mathrm{l}$ of SEWS-M (MP Biomedicals). The pellet was dried for $30 \mathrm{~min}$ in a horizontal flow hood. DNA was resuspended in $50 \mu \mathrm{l}$ of sterile distilled water, transferred to a fresh microcentrifuge tube, and was stored at $-20^{\circ} \mathrm{C}$.

Design of species-specific primers for $G$. citri-aurantii and G. geotrichum based on endo-polygalacturonase and $\beta$-tubulin gene sequences and PCR conditions used. Primers targeting the endo-polygalacturase gene were designed from sequences for $G$. citri-aurantii and G. geotrichum deposited in GenBank (accession numbers AB062510.1 and AB062511.1, respectively). Sequences were aligned using Clustal-W (version 2.0) (12,20). From the variable region of the sequence, we designed primers Gca F2 (5'AGTTCTTTGCCGCTCACAAGC-3') and Gca R2 (5'-GGAAC TTGACACCGCCTGATA-3') for $G$. citri-aurantii and primers Gc F1 (5'-GGCACCACTGTTATCTTTGACG-3') and Gc R3 (5'CGGTTACCAGAGTTGACAGC-3') for G. geotrichum using the software Primer-3 (version 4.0) (27). To design species-specific primers from the $\beta$-tubulin gene, partial $\beta$-tubulin sequences were amplified from four isolates of $G$. citri-aurantii (originating from 
California, Mexico, and China) and five isolates of G. geotrichum (originating from California, Brazil, Egypt, India, and Japan) using primers $\mathrm{Bt} 2 \mathrm{a}$ and $\mathrm{Bt} 2 \mathrm{~b}$ (18). PCR products were purified using ExoSAP-IT (USB Corporation, Cleveland, $\mathrm{OH}$ ), and sequenced at the Core Instrumentation Facility of the University of California Riverside, Institute for Integrative Genome Biology. Sequences were aligned using Clustal-W, and species-specific primers were designed using Primer-3 from a sequence region that was consistently variable between the two species but homogeneous among isolates of each species. Primers that we designed were Gca F3 (5'-GAAACCATTTCTGGCGAAC-3') and Gca R3 (5'-AGAACAGCTCTGGGGACGTA-3') for G. citri-aurantii and Gc F5 (5'-CAAACTCCCTAGGCCTTATTC-3') and Gc R6 (5'ACACCAGGCTCCAGATCAAC-3') for G. geotrichum.

PCR amplifications were performed in a total volume of $25 \mu \mathrm{l}$ containing $1 \mu \mathrm{l}$ of DNA, $2 \mu \mathrm{l}$ of dNTPs (2.5 mM each dNTP), $2.5 \mu \mathrm{l}$ of PCR buffer (New England Biolabs, Inc., Ipswich, MA), $0.25 \mu \mathrm{l}$ of bovine serum albumin $(10 \mathrm{mg} / \mathrm{ml})$ (Sigma-Aldrich Inc.), $1 \mu \mathrm{l}$ of each primer $(10 \mu \mathrm{M})$, and $0.25 \mu \mathrm{l}$ of Taq DNA polymerase (New England Biolabs). Amplifications were performed in a PCT-100 Programmable Thermal Controller (MJ Research Inc., Watertown, MA) programmed as follows: $2 \mathrm{~min}$ at $94^{\circ} \mathrm{C}$; followed by 35 cycles of $30 \mathrm{~s}$ at $94^{\circ} \mathrm{C}, 30 \mathrm{~s}$ at $62^{\circ} \mathrm{C}$, and $30 \mathrm{~s}$ at $72^{\circ} \mathrm{C}$; and a final extension at $72^{\circ} \mathrm{C}$ for $10 \mathrm{~min}$. PCR products were visualized in $1.5 \%$ (primers based on endo-polygalacturase) or $2 \%$ (primers based on $\beta$-tubulin) agarose gels after ethidium bromide staining.

Determination of mating type for isolates of Galactomyces spp. Mating type tester strains used were $G$. citri-aurantii $\mathrm{A}_{1}$ (isolate Gca $130=$ Butler 1671) and $\mathrm{A}_{2}$ (isolate Gca $126=$ Butler 1655) and G. geotrichum $\mathrm{A}_{2}$ (isolates Gc $109=$ Butler 1619 and Gc 121 = Butler 1648; no $\mathrm{A}_{1}$ tester strain was available for this species) $(9,10)$. Loops of conidia from single-spore cultures from PDA plates were streaked onto fresh PDA in $60-\mathrm{mm}$ petri dishes. Loops of conidia from single-spore isolates of unknown mating type were then streaked perpendicularly over the first streak. After 5 to 10 days of incubation at $25^{\circ} \mathrm{C}$ in the dark, vertical sections of the agar $(\approx 1 \mathrm{~mm}$ thick $)$ were mounted onto glass slides for microscopic observation at $\times 400$ magnification. For $G$. citri-aurantii, a mating type of $A_{1}$ was assigned to an isolate when asci were present in pairings with the $A_{2}$ but not with the $A_{1}$ tester strain, and a mating type of $A_{2}$ was assigned when asci were present in pairings with the $\mathrm{A}_{1}$ but not with the $\mathrm{A}_{2}$ tester strain. For G. geotrichum, a mating type of $\mathrm{A}_{1}$ was assigned to an isolate when asci were present in pairings with each of the $A_{2}$ tester strains. To test for monogenic segregation of the mating type locus within $G$. citri-aurantii, 12 randomly selected $\mathrm{A}_{1}$ and $\mathrm{A}_{2}$ isolates each were crossed against each other.

TABLE 1. Isolates of Galactomyces citri-aurantii and G. geotrichum used in this study ${ }^{\mathrm{a}}$

\begin{tabular}{|c|c|c|c|c|c|}
\hline Species, isolate code & Number $^{\mathrm{b}}$ & Population $^{\mathrm{c}}$ & Collection date $^{\mathrm{d}}$ & Source & Geographic origin \\
\hline \multicolumn{6}{|l|}{ G. citri-aurantii } \\
\hline 2 & 1 & Kern & 2006 & Lemon & Maricopa, CA \\
\hline 14 & 1 & Kern & 2006 & Navel orange & Edison, CA \\
\hline $246-248$ & 3 & Kern & 2008 & Mandarin & Maricopa, CA \\
\hline 81 & 1 & Tulare & 2007 & Citrus soil & Exeter, CA \\
\hline $\begin{array}{l}151-153,155-160,163-165,167,168,171,173, \\
182-183,185-186\end{array}$ & 21 & Tulare & 2008 & Citrus soil & Exeter, CA \\
\hline 23 & 1 & Tulare & 2007 & Valencia orange & Lindsay, CA \\
\hline $149,150,175$ & 3 & Tulare & 2008 & Citrus soil & Lindsay, CA \\
\hline $3-5,13,84,87,91$ & 7 & Tulare & 2006 & Lemon & Porterville, CA \\
\hline 89 & 1 & Ventura & 2007 & Grapefruit & Fillmore, CA \\
\hline $131,133,136-139,141-143,145-147$ & 12 & Ventura & 2007,2008 & Citrus soil & Fillmore, CA \\
\hline $188-195,199,200$ & 10 & Ventura & 2006-2008 & Lemon & Oxnard, CA \\
\hline $32,40,45,48,73,77,88$ & 7 & Ventura & 2006, 2007 & Lemon & Santa Paula, CA \\
\hline 130 & 1 & Outside & 1963 & Lemon & Trinidad \\
\hline 124 & 1 & Outside & 1986 & Soil & Argentina \\
\hline 127 & 1 & Outside & 1986 & Soil & China \\
\hline \multicolumn{6}{|l|}{ G. geotrichum } \\
\hline $102,110,117,118,121$ & 5 & California & $1957,1963,1969,1984,1986$ & Soil & California \\
\hline 231,232 & 2 & California & NA & Soil & Riverside County, CA \\
\hline $86,235,238,242-244$ & 6 & California & $2000,2005,2006$ & Peach & Fresno County, CA \\
\hline $75,132,135,140,144$ & 5 & California & 2007,2008 & Citrus soil & Ventura County, CA \\
\hline 237 & 1 & Outside & 1973 & Soil & Pennsylvania \\
\hline 106 & 1 & Outside & 1963 & Soil & Brazil \\
\hline 104,234 & 2 & Outside & 1963 & Soil & Egypt \\
\hline 100,111 & 2 & Outside & 1963 & Soil & Israel \\
\hline $99,103,233$ & 3 & Outside & 1963 & Soil & Japan \\
\hline
\end{tabular}

a Positive species identification as G. citri-aurantii or Geotrichum candidum was based on the use of species-specific polymerase chain reaction primers derived from $\beta$-tubulin and endo-polygalacturonase sequences and growth characteristics in a lemon juice assay.

${ }^{\mathrm{b}}$ Number of isolates; total Galactomyces citri-aurantii isolates $=97$ and total G. geotrichum isolates $=35$.

${ }^{\mathrm{c}}$ Populations were assigned based on geographic origin: three counties of California and outside of California (Outside) for G. citri-aurantii and California and Outside for G. geotrichum.

${ }^{\mathrm{d}} \mathrm{NA}=$ sample date not available 
AFLP procedures. AFLP reactions were performed using a modified protocol by Vos et al. (37). The restriction-ligation reaction contained $\approx 50 \mathrm{ng}$ of genomic DNA, $5 \mathrm{U}$ of EcoRI, $1 \mathrm{U}$ of MseI, $20 \mathrm{U}$ of T4 DNA ligase (all enzymes from New England BioLabs), $5 \mu \mathrm{M}$ EcoR1 adapter, $50 \mu \mathrm{M}$ MseI adapter, $1 \times$ ligase buffer, $5 \mu \mathrm{g}$ of bovine serum albumin, and $50 \mathrm{mM} \mathrm{NaCl}$ in a final volume of $11 \mu \mathrm{l}$. After incubation at $37^{\circ} \mathrm{C}$ for 2 to $2.5 \mathrm{~h}, 90 \mu \mathrm{l}$ of $\mathrm{TE}_{0.1}$ (10 mM Tris and $0.1 \mathrm{mM}$ EDTA, pH 8) was added and the reaction was stored at $-20^{\circ} \mathrm{C}$. Amplifications were done in a final volume of $12.5 \mu \mathrm{l}$ using $1.3 \mu \mathrm{l}$ of the diluted digestion-ligation reaction, $200 \mu \mathrm{M}$ of each $\mathrm{dNTP}, 0.8 \mu \mathrm{M}$ Mse primer, $0.16 \mu \mathrm{M}$ 6carboxyhexachlorofluorescein- or 6-carboxyfluorescein-labeled EcoRI primer, $1 \mu \mathrm{g}$ of bovine serum albumin, $1 \times$ Taq polymerase buffer, and $0.75 \mathrm{U}$ of $\mathrm{Taq}$ DNA polymerase (New England BioLabs). Sixteen primer pairs were initially screened for amplification. Four primer pairs were then chosen for analysis of $G$. citri-aurantii and six primer pairs for $G$. geotrichum based on reproducibility and presence of easily distinguishable polymorphic bands. These EcoRI (5'-GACTGCGTACCAATTC+2-3') and MseI (5'-GACGATGAGTCCTGAGTA+2-3') primers are listed in Table 2.

PCR conditions comprised an initial touchdown phase of 13 cycles of $94^{\circ} \mathrm{C}$ for $30 \mathrm{~s}, 65^{\circ} \mathrm{C}$ for $30 \mathrm{~s}$, and $72^{\circ} \mathrm{C}$ for $60 \mathrm{~s}$, lowering the annealing temperature by $0.7^{\circ} \mathrm{C}$ at each successive cycle; followed by 23 cycles of $94^{\circ} \mathrm{C}$ for $30 \mathrm{~s}, 56^{\circ} \mathrm{C}$ for $30 \mathrm{~s}$, and $72^{\circ} \mathrm{C}$ for $60 \mathrm{~s}$; and a final extension step of $72^{\circ} \mathrm{C}$ for $5 \mathrm{~min}$. Aliquots of $0.5 \mu \mathrm{l}$ of PCR reaction were mixed with $0.125 \mu \mathrm{l}$ of GeneScan500 LIZ size standard (Applied Biosystems, Carlsbad, CA) and denatured with $9.875 \mu \mathrm{l}$ of Hi-Dye formamide (Applied Biosystems) in a total volume of $11 \mu \mathrm{l}$ for $3 \mathrm{~min}$ at $94^{\circ} \mathrm{C}$. AFLP fragments were separated with an ABI 3100 genetic analyzer (Applied Biosystems) and analyzed using the GeneScan software (Applied Biosystems). To validate reproducibility of the procedure, each AFLP reaction run included one or several "standard" isolates and the analysis was done at least twice for each isolate. Additionally, we repeated AFLP reactions using reextracted DNA from $\approx 50 \%$ of the isolates.

Unweighted pair-group method with arithmetic mean clustering analysis and population genetic analysis of AFLP data. GeneScan AFLP data files were imported into Genographer software (version 2.1, http://sourceforge.net/projects/genographer) for visual analysis. AFLP profiles were analyzed in the 80 - to $350-\mathrm{bp}$ size range on a reconstructed gel, and consistent fragments with band intensities of $>85$ units were scored for their presence or absence among isolates. Fragments were considered individual loci that were either present (a scoring of 1) or absent (a scoring of 0), and a binary data matrix was created. AFLP.dat (17) was used to generate input files and linkage disequilibrium was evaluated for the complete data sets in Arlequin 3.1 (Excoffier, Laval, and Schneider, University of Berne, Switzerland). Any highly linked loci $(\alpha=0.05)$ were combined into a single representative locus because inclusion of highly linked loci has the effect of reducing the power of multilocus genetic analysis to accurately determine the degree of genetic diversity within a population $(2,22)$.

The binary data matrix was subjected to phenetic analyses using the unweighted pair-group method with arithmetic mean clustering (UPGMA) method of PAUP version 4.0 (34) and the tree was viewed by using TreeView (25). Statistical support for the calculated topology was conducted in a bootstrap analysis with 1,000 replications.

For population genetic analyses, two data sets were generated for each species, one using all isolates and one that was clone corrected (unique haplotypes). For this, Arlequin 3.1 was used. The proportion of polymorphic loci in each subpopulation (i.e., a geographically defined subsample of the total population) was calculated. Polymorphic loci were defined as those where the most common allele is present at a frequency of $<0.95$ (39). Haplotypic (genotypic) diversity was defined as the probability that two individuals from within a population sampled at random have distinct genotypes (2). It was calculated with the full data sets for each subpopulation as $(n / n-1)\left(1-\Sigma_{P i}{ }^{2}\right)$, where $n$ is the number of individuals sampled and $P i$ is the frequency of the $i$ th genotype of both species using MultiLocus 1.3 (2) (http://www.agapow.net/ software/multilocus/1.3b). Haplotypic diversity has a value of 1 when each individual is different and a value of 0 when each individual in a population is the same. Significance $(P)$ of the test was determined using randomization (500 times) procedures by comparing the observed haplotypic diversity with that expected under the null hypothesis of random mating (30).

Clone-corrected AFLP data for subpopulations of G. citriaurantii and G. geotrichum were subjected to an analysis of molecular variance (AMOVA) using Arlequin 3.1. Subpopulations for $G$. citri-aurantii were based on three sampling counties in California (Kern, Tulare, and Ventura) and locations outside of California (i.e., subpopulation "Outside"). For G. geotrichum, isolates were divided into a California and an Outside subpopulation. The index of genetic difference (fixation index $\left[F_{S T}\right]$ ) between populations by pairwise difference (38) and allele frequencies for each locus and subpopulation were calculated using Arlequin 3.1.

Random mating was evaluated using three approaches. First, a $\chi^{2}$ analysis of mating-type segregation was conducted $(\alpha=0.05)$ for $G$. citri-aurantii using an expected ratio of $1: 1$ for randomly mating haploid fungal populations (22). Two additional tests were done for both species of Galactomyces using the full linkageadjusted as well as the clone-corrected data sets to account for the effects of reduced sample size due to removal of clone-mates on the probability of rejecting the null hypothesis of random mating in statistical tests (22). The index of association $\left(\mathrm{I}_{\mathrm{A}}\right)$ that tests the random association among loci was calculated from AFLP data using MultiLocus 1.3. For a randomly mating population without linked loci, the theoretical value for $\mathrm{I}_{\mathrm{A}}$ is zero. The significance $(P)$ of $\mathrm{I}_{\mathrm{A}}$ was tested by comparing the value for the observed data with randomized data (500 times; $\alpha=0.05$ ) to assess significant deviations from gametic equilibrium expected with panmixis (2).

TABLE 2. Selective primer pairs used in amplified fragment length polymorphism reactions for two species of Galactomyces

\begin{tabular}{|c|c|c|c|}
\hline \multirow[b]{2}{*}{ MseI primers (adapter +2 ) } & \multirow[b]{2}{*}{ EcoRI primers (label, adapter +2$)^{\mathrm{a}}$} & \multicolumn{2}{|c|}{ Number of markers ${ }^{b}$} \\
\hline & & Galactomyces citri-aurantii & G. geotrichum \\
\hline $5^{\prime}-\mathrm{TC}-3^{\prime}$ & $5^{\prime}$-FAM-AC-3' & 20 & 9 \\
\hline $5^{\prime}-\mathrm{AC}-3^{\prime}$ & 5'-HEX-TA-3' & 23 & 11 \\
\hline $5^{\prime}-\mathrm{TT}-3^{\prime}$ & 5'-FAM-CA-3' & 10 & 13 \\
\hline $5^{\prime}-\mathrm{GC}-3^{\prime}$ & 5'-HEX-TA-3' & 15 & $\ldots$ \\
\hline $5^{\prime}-\mathrm{GA}-3^{\prime}$ & 5'-FAM-AC-3' & $\ldots$ & 11 \\
\hline $5^{\prime}-\mathrm{TA}-3^{\prime}$ & 5'-FAM-AC-3' & $\ldots$ & 18 \\
\hline $5^{\prime}-\mathrm{TG}-3^{\prime}$ & 5'-HEX-TA-3' & $\ldots$ & 11 \\
\hline Total & & 68 & 73 \\
\hline
\end{tabular}

${ }^{\mathrm{a}} \mathrm{HEX}=6$-carboxyhexachlorofluorescein and FAM = 6-carboxyfluorescein.

${ }^{\mathrm{b}}$ Consistently amplified DNA fragments scored as being potentially descriptive. 
The third test to determine the reproductive mode was the parsimony tree-length permutation test (PTLPT) (6). PTLPT compares the length of the observed tree to trees produced with randomized data and is a phylogenetic approach based on the concept that a clonal population should produce a single well-resolved tree with little homoplasy and shorter tree branches than a sexually reproducing population due to the reassortment of alleles during meiosis (35). Output data files from MultiLocus 1.3 were analyzed using PAUP version 4.0. The significance of the test $(P)$ was determined using randomization procedures by comparing the observed tree length to the tree lengths of 500 simulated recombined data sets (6).

\section{RESULTS}

Growth characteristics of isolates of Galactomyces spp. in lemon juice. Most isolates evaluated were assigned to either of two growth patterns when incubated in undiluted, autoclaved lemon juice. Cultures identified previously as G. geotrichum by others (10), several cultures originating from non-citrus environments, and five isolates from soil in citrus groves in California formed clusters of mycelial colonies with irregular branching, and few individual conidia were present (Fig. 1A). In contrast, growth of isolates assigned to G. citri-aurantii based on their origin from citrus fruit or from soil in citrus groves occurred as elongated cells that fragmented into numerous individual conidia, and no mycelial clusters were present (Fig. 1B). Several isolates did not grow in undiluted lemon juice but exhibited characteristic structures when incubated in lemon juice diluted $50 \%$ with sterile

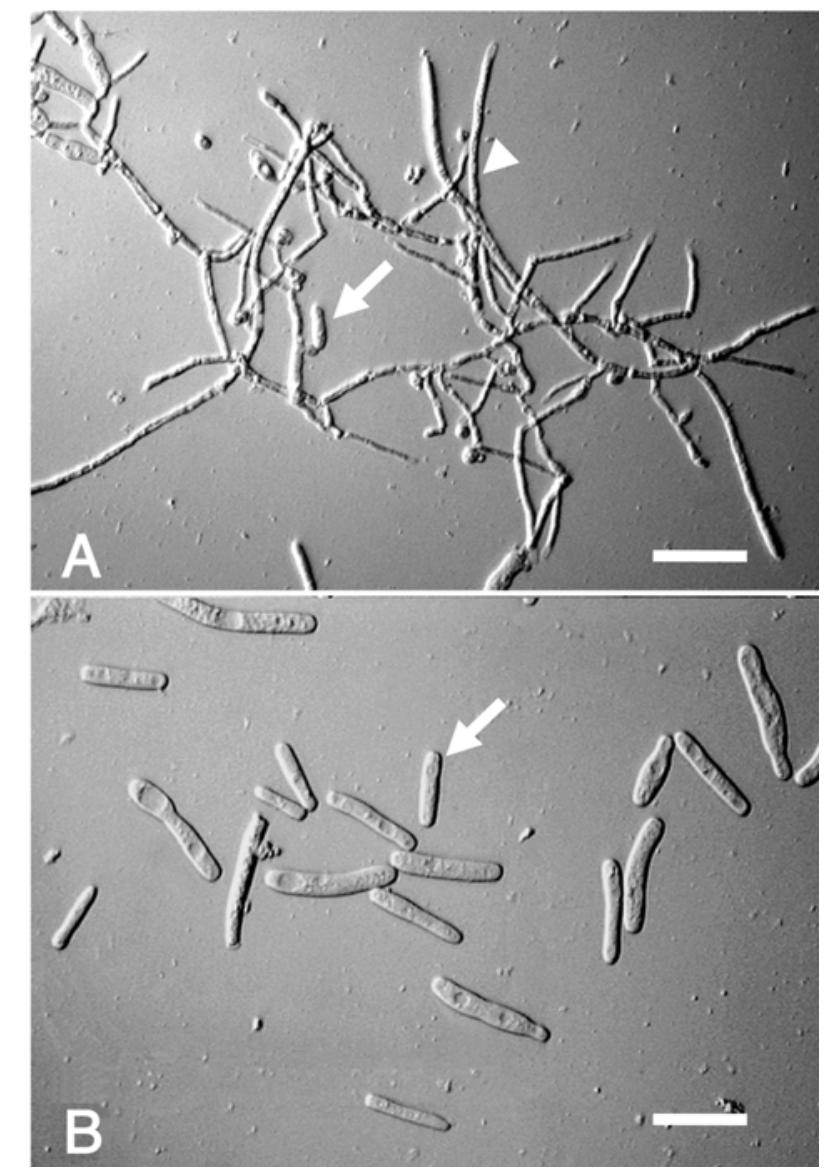

Fig. 1. Growth characteristics of A, Galactomyces geotrichum and B, G. citriaurantii in autoclaved lemon juice at $\mathrm{pH} 2.2$. For G. geotrichum, growth occurred as small filamentous colonies (arrowhead) with irregular branching and with only few individual conidia (arrow). For G. citri-aurantii, growth occurred as elongated cells that fragmented into numerous individual conidia (arrow). Scale bar $=50$ and $15 \mu \mathrm{m}$ for A and B, respectively. water. Thus, all isolates could be placed into either of the two growth pattern groups and separated into the two species, as indicated in Table 1.

PCR amplifications using species-specific primers for $G$. citri-aurantii and G. geotrichum. After PCR amplification, primers based on endo-polygalacturonase gene sequences yielded DNA fragments of $441 \mathrm{bp}$ in size for all isolates assigned to $G$. citri-aurantii (Fig. 2A) and fragments of 434 bp in size for isolates assigned to G. geotrichum (Fig. 2B). However, faint background bands were frequently observed for each species using primers designed for the other species (Fig. 2A and B), even when annealing temperatures were increased to $>62^{\circ} \mathrm{C}$. Primers designed from $\beta$-tubulin gene sequences yielded specific bands for G. citri-aurantii (Fig. 2C) and G. geotrichum (Fig. 2D) of 208 and $152 \mathrm{bp}$ in size, respectively, and no background bands were observed.

Determination of mating type for isolates of Galactomyces spp. For G. citri-aurantii, asci were easily observed microscopically in most pairings of mating type tester strains with isolates of unknown mating type. Asci typically developed in clusters, mainly at 1 to $3.5 \mathrm{~mm}$ below the agar surface (Fig. 3). Asci were spherical and 7 to $12 \mu \mathrm{m}$ in diameter. Of the total 87 isolates evaluated, 52 isolates were determined to be of $A_{1}$ and 35 isolates of $A_{2}$ mating type. In 10 of the pairings, ascospores failed to develop in repeated evaluations. In tests for the monogenic segregation of the mating type locus in G. citri-aurantii, asci were observed for all $A_{1}$ to $A_{2}$ pairings.

For the 35 isolates evaluated for G. geotrichum, asci in pairings with $\mathrm{A}_{2}$ tester strains Gc 109 and Gc 121 were only observed for two isolates (i.e., 78 and 86). Asci were similar in appearance as for $G$. citri-aurantii but were produced much less abundantly.

UPGMA analysis and population genetic analysis of AFLP data. AFLP banding patterns were reproducible based on repeated DNA extractions and repeated reactions, including two
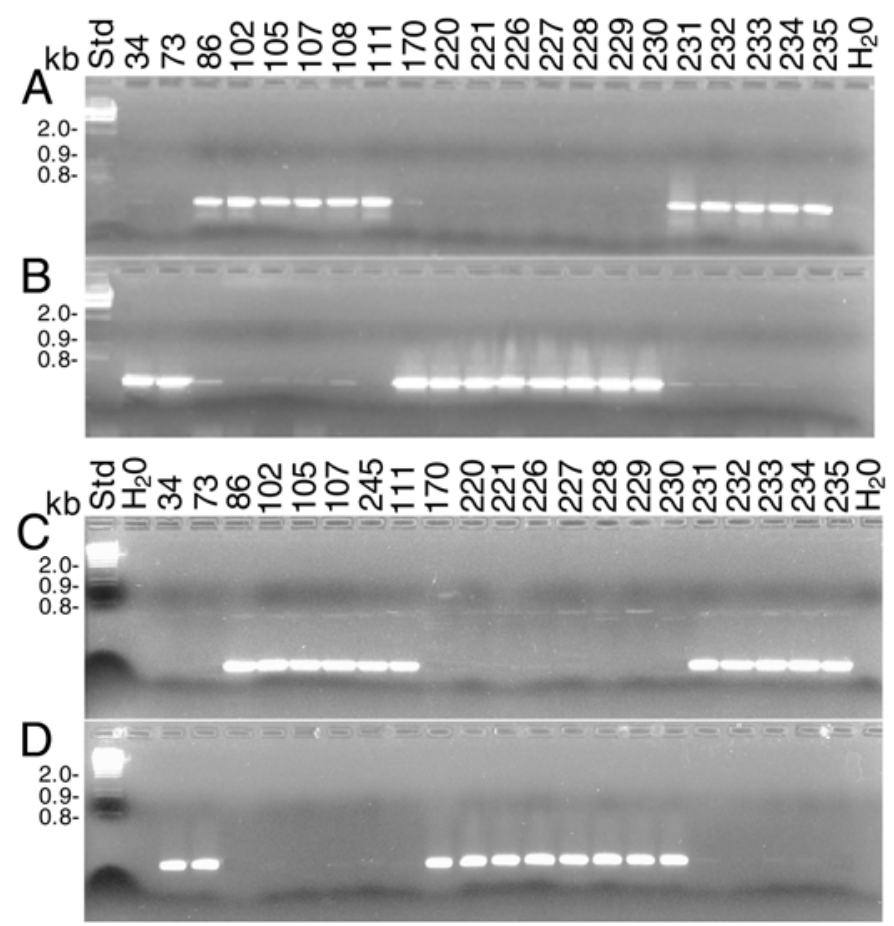

Fig. 2. Polymerase chain reaction amplifications using species-specific primers developed from DNA sequences of $\mathbf{A}$ and $\mathbf{B}$, endo-polygalacturonase or $\mathbf{C}$ and $\mathbf{D}$, $\beta$-tubulin genes for identification of $\mathbf{A}$ and $\mathbf{C}$, Galactomyces geotrichum and $\mathbf{B}$ and $\mathbf{D}$, G. citri-aurantii. Primer pairs used for the identification of G. geotrichum were Gc F1/Gc R3 and Cand F5/Cand R6; and of G. citri-aurantii were Gca F2/Gca R2 and Citri F3/Citri R3 for the endopolygalacturonase and $\beta$-tubulin genes, respectively. 
amplifications for each isolate. Examples of reconstructed AFLP gels for representative isolates of $G$. citri-aurantii and $G$. geotrichum using two primer pairs are shown in Figure 4A and B. Both species are clearly differentiated by their distinct banding patterns. For 97 isolates of G. citri-aurantii, 68 DNA fragments were scored initially following AFLP analysis with four primer pairs (Table 2). After analysis of genetic linkage and removal of polymorphic bands that were only present in single isolates, the final database for this species comprised 19 polymorphic fragments. For 35 isolates of G. geotrichum, 73 DNA fragments were scored initially following AFLP analysis with six primer pairs (Table 2) and the final database comprised 11 polymorphic fragments.

UPGMA analyses generated a dendrogram with a high degree of diversity for each species; however, only a few branching nodes showed strong support in the bootstrap analysis (Figs. 5 and 6). Few clonal groups were identified for each species. The largest clonal group for G. citri-aurantii comprised six isolates (i.e., 143, 192, 193, 194, 195, and 199) that originated from fruit and soil at two locations in Ventura County. The remaining nine smaller clonal groups each contained isolates from the same or different areas within California. The larger of the two clonal groups found in G. geotrichum contained isolates (i.e., isolates $102,238,242,243$, and 244) from peach and soil in California collected over a period of $>20$ years, whereas the smaller clonal group contained isolates (i.e., isolates 121, 140, and 144) from soil in California, including two isolates from citrus groves. The dendrogram for $G$. geotrichum includes three divergent isolates (i.e., isolates 101, 105, and 108) that originated from India, an unknown location, and Zimbabwe, respectively (Fig. 6).

Data analysis for G. citri-aurantii using Arlequin 3.1 where linked loci were combined identified a total of 82 unique haplotypes for the four subpopulations and, of these, 80 haplotypes were unique among subpopulations. Of the total number of AFLP loci scored, the Ventura County subpopulation had the highest and the Kern County subpopulation had the lowest proportion of polymorphic loci (Table 3). For all subpopulations of this species, haplotypic diversity was high and the Outside subpopulation had the highest value (Table 3). Nei's gene diversity values were 0.164 to 0.302 . For $G$. geotrichum, 26 unique haplotypes were identified among the two subpopulations and no haplotype was shared for the two subpopulations. The proportion of polymorphic loci and haplotypic diversity were high and Nei's gene diversity values were 0.275 to 0.369 .

Indices of genetic differences $\left(F_{S T}\right)$ between subpopulations of G. citri-aurantii that were calculated by pairwise comparisons were all low ( 0.085 to 0.226 ) (Table 4$)$. In these calculations, $F_{S T}$ values in all comparisons with the Outside subpopulation were the highest and were significant $(P<0.002)$, indicating the highest divergence of this subpopulation (Table 4). In contrast, the Tulare County subpopulation showed the least divergence from the one from Ventura County $\left(F_{S T}\right.$ value $\left.0.085 ; P<0.001\right)$. For $G$. geotrichum, the pairwise $F_{S T}$ value for the two geographically defined subpopulations was $0.038(P=0.094)$, indicating a low level of genetic differentiation.

Allele frequencies that were calculated using clone-corrected data were generally consistent across the four populations for individual loci; however, two loci represented by fragments $82 \mathrm{~A}$ and $226 \mathrm{D}$ were present only in the Ventura County population at low frequencies of 0.176 and 0.118 , respectively (Table 5). The Outside subpopulation lacked five alleles that were present in the total population; whereas the Kern, Tulare, and Ventura subpopulations lacked four, three, and one allele, respectively (Table 5). For the California subpopulation of G. geotrichum, allele frequencies ranged from 0.176 (locus 154C) to 0.941 (loci 117A and 98F) for the 11 loci evaluated for the final analysis; and, for the population collected from outside of California, allele frequencies ranged from 0.333 (locus 209C) to 1.00 (loci 130A and 151B).
Reproductive mode. Using non-clone-corrected data sets, the mating type distribution for G. citri-aurantii did not significantly $(P>0.1)$ deviate from a 1:1 ratio in $\chi^{2}$ tests for the Kern, Tulare, or Outside subpopulations (Table 6). Following clone correction, mating type segregation ratios did not deviate from a 1:1 ratio for all four subpopulations and the entire population. Tests of $\mathrm{I}_{\mathrm{A}}$ supported a random mating structure only for clonecorrected data for the Kern, Tulare, and Ventura subpopulations and the null hypothesis of random mating could not be rejected with values of $P>0.05$ (Table 6). The null hypothesis was rejected for non-clone-corrected data of these subpopulations and for clone-corrected and noncorrected data for the Outside subpopulation and the total population of this species. In the PTLPT analyses, probability values of 0.314 to 0.538 indicated that random mating could not be rejected for the clone-corrected data of the entire population, as well as of all four subpopulations. Thus, the lengths of the observed trees were not statistically different from those generated after randomization of the data 500 times.

For G. geotrichum, random mating was only tested using $\mathrm{I}_{\mathrm{A}}$ and PTLPT. In the $\mathrm{I}_{\mathrm{A}}$ calculations, the null hypothesis of random mating was not rejected $(P>0.05)$ except for the non-clonecorrected data for the California population (Table 6). The PTLPT analysis with $P$ values of 0.386 to 0.680 was consistent with random mating based on clone-corrected data for the two subpopulations and for the total population. For the non-clonecorrected data, the null hypothesis of random mating was only rejected $(P=0.014)$ for data of the total population.

\section{DISCUSSION}

Isolates of the morphologically similar sour rot pathogens $G$. citri-aurantii and $G$. geotrichum could be easily differentiated based on characteristic growth in a lemon juice assay and by PCR reactions using newly designed species-specific primers from the endo-polygalacturonase and $\beta$-tubulin genes. Specific primers derived from the endo-polygalacturonase gene were recently also designed and used by others to differentiate isolates pathogenic and nonpathogenic to citrus (23). These latter authors do not acknowledge that two separate species cause sour rot of fruit

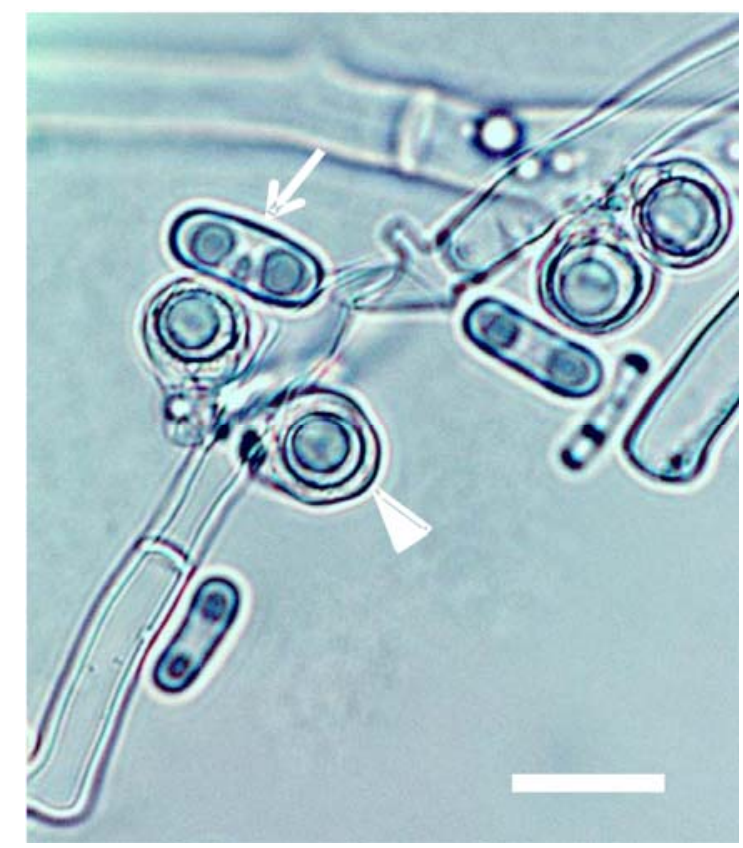

Fig. 3. Single-spored asci with thickened wall (arrowhead at one ascus) and conidia (arrow at one conidium) in a pairing of $\mathrm{A}_{1}$ and $\mathrm{A}_{2}$ mating types of Galactomyces citri-aurantii. Scale bar $=10 \mu \mathrm{m}$. 
crops and, instead, recognize a single species, G. geotrichum, with two pathogenicity types in citrus fruit assays. Our studies add to the evidence that two distinct biological and molecular species exist. The highly diverse AFLP banding patterns that we obtained for the two species with virtually no shared fragments further supports this taxonomic separation. Growth and molecular assays for species identification in our study ensured that isolates were properly classified before analyses of population structure were done. Although G. citri-aurantii has been ecologically associated with the citrus environment such as citrus fruit or soil from citrus groves (9), exceptions are known. For example, isolates of $G$. geotrichum have been recovered from citrus groves and, likewise, isolates of $G$. citri-aurantii have been obtained from non-citrus environments (31). Similarly, in our study, five isolates of $G$. geotrichum were recovered from soil in citrus groves.

Haplotypic diversity values were high for all four subpopulations of $G$. citri-aurantii, indicating high genetic differences among individual haplotypes. The California subpopulations showed a moderate gene diversity whereas the Outside subpopu- lation showed higher average gene diversity over all loci (Nei's gene diversity values). Similar to most of the subpopulations of G. citri-aurantii, those of G. geotrichum had a high proportion of polymorphic loci and high haplotypic diversity. Average gene diversity was moderate to high in this latter species, considering that the maximum value for a panmictic population is 0.5 for biallelic markers (39) such as the AFLPs reported here. The genotypic diversity could be explained by sexual recombination within each subpopulation. Even low frequencies of recombination, however, may produce a population structure that has all the appearances of random mating (22). Mutation is unlikely the cause for the diversity found, because random mutations would result in novel alleles not widely shared among subpopulations. In the analysis of allele frequencies for $G$. citri-aurantii, only two alleles were unique to a single subpopulation.

Ascospores of Galactomyces spp. can be obtained in pairings with isolates of the opposite mating type in the laboratory; ascospores of $G$. citri-aurantii have been observed in decaying lemon fruit and are assumed to occur in the field (9). Furthermore, isolates of G. citri-aurantii with wide phenotypic diversity

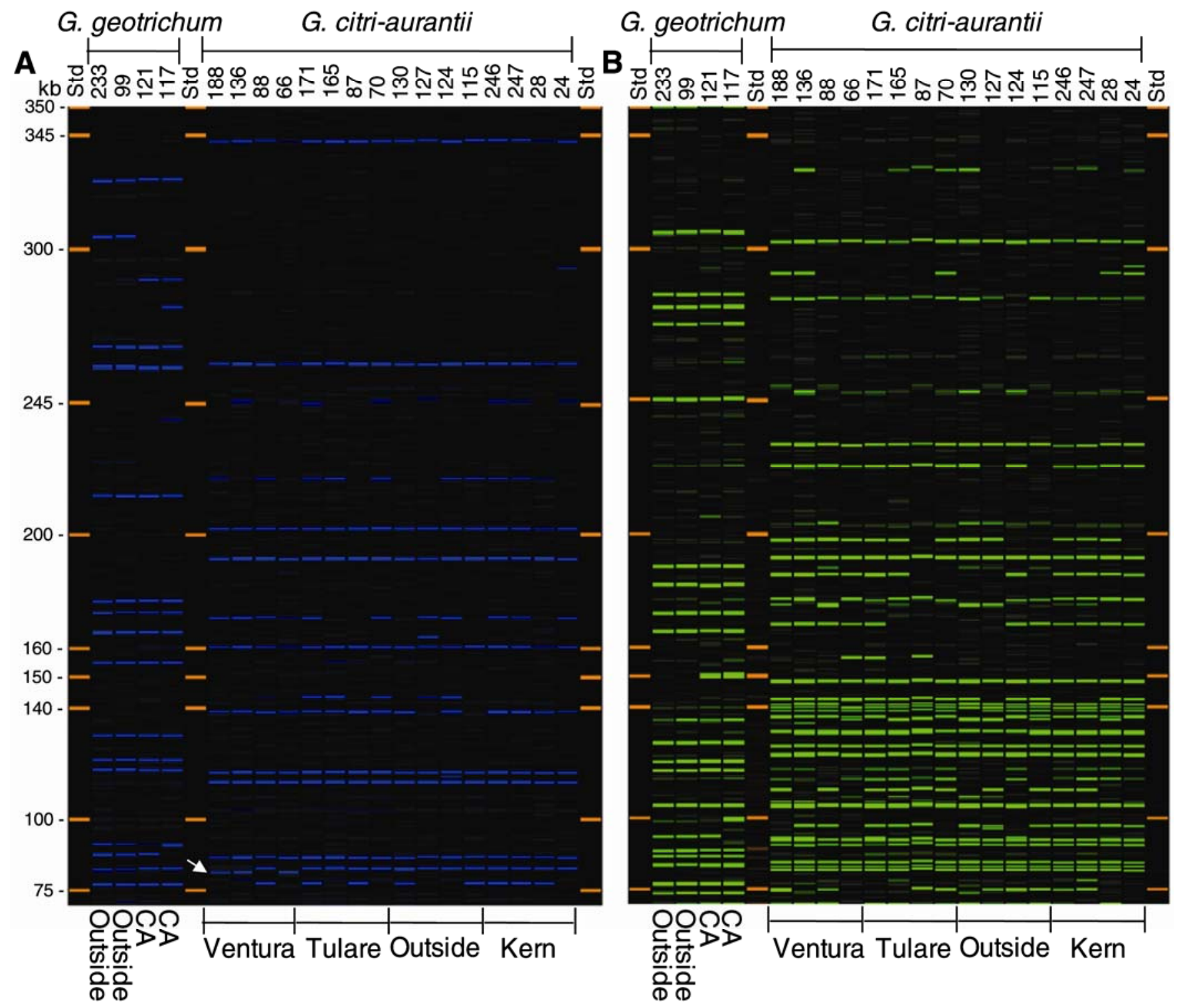

Fig. 4. Reconstructed image of an amplified fragment length polymorphic DNA gel using Genographer (version 2.1) for Galactomyces citri-aurantii and G. geotrichum. Primer pairs A, EcoR1-AC-6-carboxyfluorescein + MseI-TC and B, EcoR1-TA-6-carboxyhexachlorofluorescein $+M s e I-A C$ were used. In all, 4 isolates of G. geotrichum representing two subpopulations (California and outside of California [Outside]) and 16 isolates of G. citri-aurantii representing four subpopulations (Kern, Tulare, Ventura, and Outside) are depicted for each set of primers. The GS-500-LIZ standard was used and sizes of each fragment are shown. 
have been recovered from citrus grove soils worldwide $(19,33)$ and both mating types have been isolated from soil under the same citrus trees (9). The significance of sexual reproduction in generating genotypic diversity in the field has remained unclear.

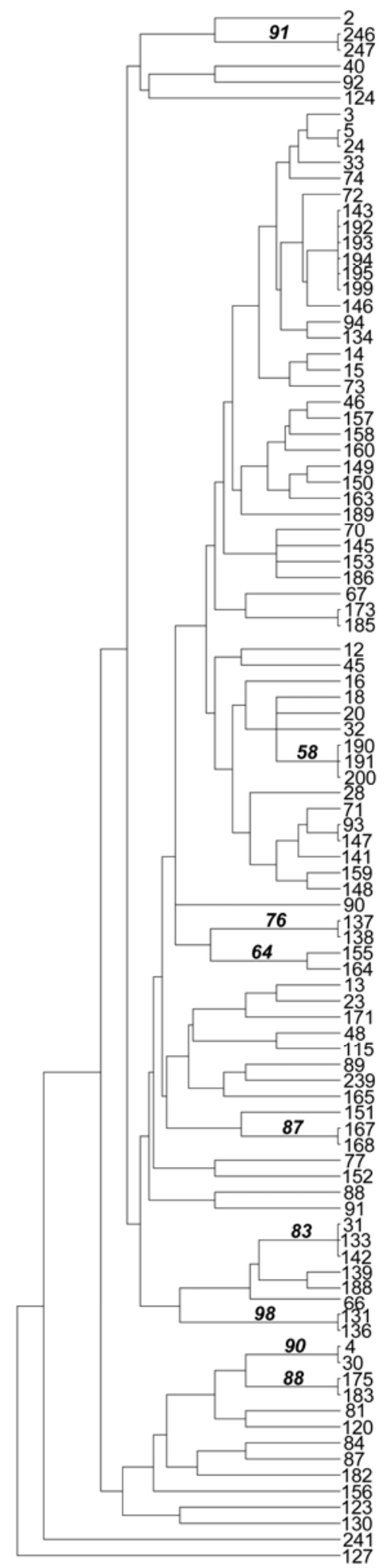

Fig. 5. Dendrogram generated with the unweighted pair-group method with arithmetic mean clustering for 97 isolates of Galactomyces citri-aurantii using 52 amplified fragment length polymorphic fragments (19 polymorphic fragments). Isolate numbers are shown on the right side of the tree at the branch ends. Clones are shown by a vertical line at the end of the branch followed by the isolate numbers. Numbers in bold italic at the nodes are bootstrap values based on 1,000 replications and only values $>50 \%$ are shown.
Not all tests that we conducted supported evidence for random mating but there is a strong indication that sexual reproduction of both species of Galactomyces does occur in the field. This finding and the overall genetic diversity observed could have practical implications for the management of sour rot diseases. For example, pathogens with large genetic diversity and the ability to adapt through sexual means are thought to be more likely to develop resistance against a fungicide (21).

Subpopulations within both species were defined based on the geographic origin of the isolates. $F_{S T}$ values in pairwise comparisons of subpopulations were all low. Still, for G. citriaurantii, $F_{S T}$ values were higher in comparisons between the Outside subpopulation and the three California subpopulations than in comparisons among the California subpopulations. Thus, subpopulations were not strongly differentiated genetically, indicating that gene flow and migration may be important in shaping the population structure of these pathogens. Moreover, the number of shared alleles among subpopulations of $G$. citri-aurantii was relatively high for most of the loci (e.g., 17 of 25). This may reflect the difficulty of defining subpopulations in some agricultural host-pathogen systems. Although both species of Galactomyces are soil fungi, conidia are not airborne, and inoculum in the field is not easily dispersed long distances. Still, conidia are produced in extremely high quantities on decaying fruit and commodities are often shipped long distances from the orchard to the packinghouse and, subsequently, to market. Furthermore, contaminated harvest bins may be taken to distant locations upon demand and decayed cull fruit in the packinghouse are sometimes

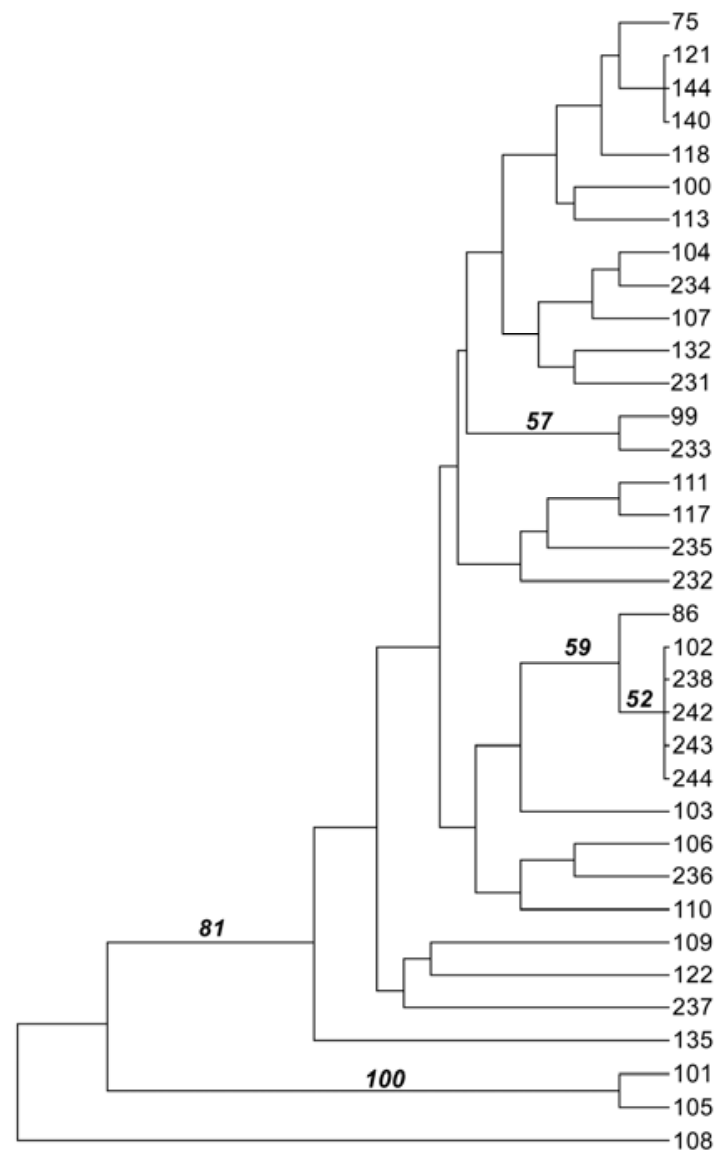

Fig. 6. Dendrogram generated with the unweighted pair-group method with arithmetic mean clustering for 36 isolates of Galactomyces geotrichum using 73 amplified fragment length polymorphic fragments (11 polymorphic fragments). Isolate numbers are shown on the right side of the tree at the branch ends. Clones are shown by a vertical line at the end of the branch followed by the isolate numbers. Numbers in bold italic at the nodes are bootstrap values based on 1,000 replications and only values $>50 \%$ are shown. 
TABLE 3. Population genetic statistics for Galactomyces citri-aurantii and G. geotrichum

\begin{tabular}{|c|c|c|c|c|c|c|}
\hline \multirow[b]{2}{*}{ Species, subpopulation } & \multicolumn{2}{|c|}{ Sample size } & \multirow[b]{2}{*}{ Proportion of polymorphic loci ${ }^{\mathrm{a}}$} & \multicolumn{3}{|c|}{ Diversity } \\
\hline & Total & Clone-corrected & & Haplotypic ${ }^{b}$ & $P$ & Nei's gene \\
\hline \multicolumn{7}{|l|}{ G. citri-aurantii } \\
\hline Kern & 8 & 7 & 0.321 & 0.976 & 0.030 & 0.164 \\
\hline Tulare & 37 & 35 & 0.678 & 0.994 & 0.016 & 0.188 \\
\hline Ventura & 46 & 34 & 0.857 & 0.978 & $<0.002$ & 0.193 \\
\hline Outside & 6 & 6 & 0.607 & 1.000 & 1.000 & 0.302 \\
\hline \multicolumn{7}{|l|}{ G. geotrichum } \\
\hline California & 18 & 12 & 0.818 & 0.944 & 0.010 & 0.275 \\
\hline Outside & 17 & 14 & 1.000 & 0.987 & 0.008 & 0.369 \\
\hline
\end{tabular}

a Polymorphic loci were defined as those where the most common allele is present at a frequency of $<0.95$.

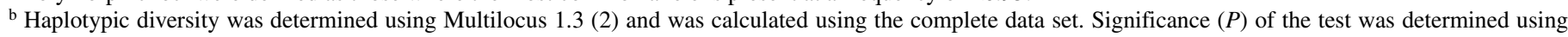
randomization (500 times) procedures by comparing the observed haplotypic diversity to that expected under the null hypothesis of random mating (30).

c Average gene diversity over all loci was calculated from clone-corrected data using Arlequin 3.1.

TABLE 4. Pairwise population indices of genetic difference $\left(F_{S T}\right)$ values for four subpopulations of Galactomyces citri-auranti $i^{\mathrm{a}}$

\begin{tabular}{lc}
\hline Comparison between subpopulations $^{\mathrm{a}}$ & $F_{S T}$ value \\
\hline Kern-Outside & 0.194 \\
Tulare-Outside & 0.149 \\
Ventura-Outside & 0.226 \\
Kern-Tulare & 0.139 \\
Kern-Ventura & 0.119 \\
Tulare-Ventura & 0.085
\end{tabular}

a Calculated between distinct subpopulations using clone-corrected data.

taken back to orchard sites, where they may be buried in the ground. Thus, individuals of the pathogen may be disseminated over large areas during agricultural activities (thus, contributing to migration and gene flow), resulting in heterogeneous populations that are not strongly separated.

For G. citri-aurantii, we found that mating type ratios did not deviate significantly from 1:1 for all subpopulations and the entire population following clone correction. Similarly, tests of $\mathrm{I}_{\mathrm{A}}$ and PTLPT supported a random mating structure for clone-corrected but not for non-clone-corrected data of most of the subpopulations. For G. geotrichum, matings with tester strains were mostly unsuccessful. Because only $\mathrm{A}_{2}$ tester strains were available, the absence of ascospores could indicate that most isolates were of the $\mathrm{A}_{2}$ mating type. Matings using the G. citri-aurantii tester strains were also unsuccessful (data not shown). Due to lack of data, no mating type segregation analysis was done. For $G$. geotrichum, the null hypothesis of random mating in the tests of $\mathrm{I}_{\mathrm{A}}$ and PTLPT was not rejected, mainly using the clone-corrected data as with $G$. citri-aurantii. Contrasting results using clone- and non-clone-corrected data sets have also been observed in other ascomycete fungi, and this has been associated with a mixed mode of mating $(13,15)$. For example, mating type ratios of the needle blight fungus Dothistroma septosporum did not deviate significantly from $1: 1$ in a diverse population but $\mathrm{I}_{\mathrm{A}}$ or PTLPT tests indicated a more clonal population structure unless clones were removed from the analysis (13). Other factors that may be contributing to the assessment of recombination in a population include linkage of loci, high mutation rates, and small sample size (22). Linkage correction was conducted for our data sets. The number of isolates of $G$. geotrichum evaluated may have been limiting. It has been suggested that 60 or more isolates should be used for multilocus evaluation of random mating (39). A final evidence from our study that sexual recombination likely occurs in both species of Galactomyces is the lack of grouping consistency in the UPGMA tree analyses. A high confidence based on bootstrap values was obtained for only a few of the nodes in each of the two trees. It has been established that recombining genotypes, such as in sexually reproducing fungal species, show little or no phylogenetic consistency because different loci reflect different patterns of descent among individuals (22).
TABLE 5. Population allele frequencies for clone-corrected amplified fragment length polymorphism data for Galactomyces citri-aurantii

\begin{tabular}{lcccc}
\hline & \multicolumn{4}{c}{ Population allele frequency ${ }^{\mathrm{a}}$} \\
\cline { 2 - 5 } Locus & Ventura & Tulare & Kern & Outside \\
\hline 210A & 0.029 & 0.171 & $\mathbf{0 . 0 0 0}$ & $\mathbf{0 . 0 0 0}$ \\
171A & 0.824 & 0.829 & 0.800 & 0.333 \\
161A & 0.882 & 1.000 & 1.000 & 1.000 \\
143A & 0.147 & 0.143 & $\boldsymbol{0 . 0 0 0}$ & 0.333 \\
138A & 0.941 & 0.914 & 1.000 & 0.333 \\
83A & 0.824 & 1.000 & 1.000 & 1.000 \\
82A & 0.176 & $\mathbf{0 . 0 0 0}$ & $\mathbf{0 . 0 0 0}$ & $\mathbf{0 . 0 0 0}$ \\
78A & 0.353 & 0.257 & 0.200 & 0.333 \\
198B & 0.353 & 0.257 & 1.000 & 0.500 \\
186B & 0.882 & 0.829 & 1.000 & 0.500 \\
177B & 0.118 & 0.743 & 1.000 & 0.333 \\
169B & 0.882 & 0.657 & 0.400 & 0.333 \\
156B & 0.029 & 0.200 & 0.400 & $\mathbf{0 . 0 0 0}$ \\
142B & 0.971 & 0.800 & 1.000 & 0.833 \\
136B & 0.971 & 0.914 & 1.000 & 0.500 \\
110B & 0.588 & 0.200 & 1.000 & 0.667 \\
98B & 0.647 & 0.171 & 0.400 & 0.883 \\
198C & 0.941 & 0.971 & 1.000 & 1.000 \\
195C & 0.118 & 0.057 & 0.200 & $\mathbf{0 . 0 0 0}$ \\
161C & 0.824 & 0.714 & 1.000 & 0.833 \\
105C & 0.912 & 0.886 & 1.000 & 0.667 \\
228D & 0.029 & $\mathbf{0 . 0 0 0}$ & 0.600 & 0.333 \\
227D & 0.853 & 0.971 & 0.400 & 0.667 \\
226D & 0.118 & $\mathbf{0 . 0 0 0}$ & $\boldsymbol{0 . 0 0 0}$ & $\mathbf{0 . 0 0 0}$ \\
148D & $\mathbf{0 . 0 0 0}$ & 0.114 & 0.200 & 0.117 \\
\hline
\end{tabular}

a Allele frequencies were based on positive alleles in the data set. Frequencies of 0.000 indicate an absence of the allele at the indicated locus for the specified subpopulation.

Based on our data, sexual reproduction seems to have a major role in the life cycle of both species of Galactomyces. As additional evidence, few clonal isolates were detected for each species. Still, the relative importance of sexual reproduction may be overestimated due to the selection of isolates used. In our own collections, isolates were obtained over several years and from diverse locations. Only between one and three isolates were included in the analyses from a single soil sampling location or fruit lot. Thus, the collection may have been biased toward more diversity. Both sour rot pathogens produce abundant asexual conidia on infected fruit that can infect healthy fruit and spread the disease and, thus, conidia are important in the disease cycle. The relative importance of sexual reproduction in both species will have to be elucidated in additional studies by using a sampling strategy where smaller sample areas (for example, soil from under a single tree) are evaluated. A mixed reproduction system with an out-crossing sexual mating system and an asexual phase with a high capacity of reproduction (21) can be proposed for $G$. citri-aurantii and $G$. geotrichum. This life cycle, with heterothallic meiosporic as well as mitosporic reproduction, was described to be most common for fungi (36). In a mixed repro- 
TABLE 6. Random mating tests for Galactomyces citri-aurantii and G. geotrichum using the full and clone-corrected (CC) data sets

\begin{tabular}{|c|c|c|c|c|c|c|c|c|c|}
\hline \multirow[b]{2}{*}{ Species, subpopulation } & \multicolumn{3}{|c|}{ Mating type segregation ${ }^{a}$} & \multicolumn{3}{|c|}{ Index of association $\left(\mathrm{I}_{\mathrm{A}}\right)^{\mathrm{b}}$} & \multicolumn{3}{|c|}{ PTLPT $^{\mathrm{c}}$} \\
\hline & $\mathrm{A}_{1}: \mathrm{A}_{2}$ & $\chi^{2}$ & $P$ & $N$ & $\mathrm{I}_{\mathrm{A}}$ & $P$ & $\mathrm{~L}$ & $\mathrm{~L}^{*}$ & $P$ \\
\hline \multicolumn{10}{|l|}{ G. citri-aurantii } \\
\hline Kern & $4: 2$ & 2.5 & $>0.5$ & 8 & 0.885 & 0.014 & $17(3)$ & 16 & 0.018 \\
\hline Tulare & $19: 16$ & 0.35 & $>0.5$ & 37 & 0.199 & 0.068 & $60(2)$ & 67 & 0.002 \\
\hline Ventura & $28: 15$ & 2.07 & $>0.1$ & 46 & 0.268 & 0.036 & $70(2)$ & 74 & 0.002 \\
\hline Outside & $2: 3$ & 0.33 & $>0.5$ & 6 & 0.785 & 0.028 & $25(1)$ & 22 & 0.328 \\
\hline Total & $52: 35$ & 1.74 & $>0.1$ & 97 & 0.373 & $<0.002$ & $156(1)$ & 156 & 0.001 \\
\hline Kern CC & $3: 1$ & 0.58 & $>0.1$ & 5 & 0.037 & 0.446 & $11(1)$ & 10 & 0.514 \\
\hline Tulare CC & $17: 15$ & 0.23 & $>0.5$ & 34 & 0.184 & 0.118 & $11(1)$ & 10 & 0.538 \\
\hline Ventura CC & $18: 15$ & 0.37 & $>0.5$ & 35 & 0.036 & 0.400 & $70(1)$ & 63 & 0.412 \\
\hline Outside CC & $2: 3$ & 0.33 & $>0.5$ & 6 & 0.785 & 0.028 & $25(1)$ & 23 & 0.314 \\
\hline Total CC & $40: 35$ & 0.33 & $>0.5$ & 80 & 0.277 & 0.002 & $161(1)$ & 155 & 0.426 \\
\hline \multicolumn{10}{|l|}{ G. geotrichum } \\
\hline California & ND & ND & ND & 18 & 0.440 & 0.010 & $18(5)$ & 15 & 0.238 \\
\hline Outside & ND & ND & ND & 17 & 0.155 & 0.154 & $24(1)$ & 21 & 0.094 \\
\hline Total & ND & ND & ND & 35 & 0.120 & 0.082 & $35(3)$ & 33 & 0.014 \\
\hline California CC & ND & ND & ND & 12 & 0.052 & 0.350 & $17(5)$ & 14 & 0.576 \\
\hline Outside CC & ND & ND & ND & 14 & 0.025 & 0.408 & $24(1)$ & 20 & 0.680 \\
\hline Total CC & ND & ND & ND & 26 & 0.024 & 0.382 & $34(1)$ & 30 & 0.386 \\
\hline
\end{tabular}

${ }^{a}$ Mating type segregation was tested using $\chi^{2}$ with an expected ratio of 1:1 $(\alpha=0.05)$. Significant deviations from 1:1 were used to reject the null hypothesis of random mating (22). Sample size for mating type $\left(\mathrm{A}_{1}\right.$ or $\left.\mathrm{A}_{2}\right)$ is less than $N$ in some populations due to missing data. ND $=$ not determined.

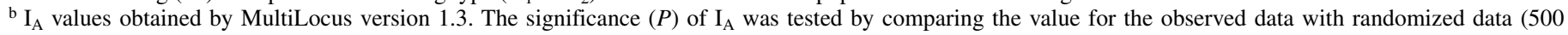
times; $\alpha=0.05$ ) to assess significant deviations from gametic equilibrium expected with random mating (2).

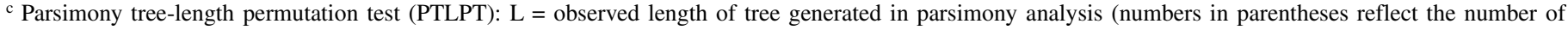
most parsimonious trees found) and $\mathrm{L}^{*}=$ length of the shortest tree for randomized data (500 replicates). The significance of the test $(P)$ was determined using randomization procedures by comparing the observed tree length (L) to the tree lengths of 500 simulated recombined data sets (6).

duction system, new recombinants derived from sexual reproduction will be continually challenged in changing environments (21). Selected genotypes will be amplified asexually and may be distributed through gene flow. In an agricultural system with numerous selection pressures imposed by human activity, this may contribute to resistance development against pesticides or the development of new pathogenicity types.

\section{ACKNOWLEDGMENTS}

We thank E. E. Butler for worldwide reference isolates in his collection and tester strains (located at University of California, Davis); S. Nadler, University of California, Davis, for advice on phylogenetic analyses; N. Nguyen, K. Nguyen, and K. Ko for technical assistance in AFLP and mating type analyses; and the California Citrus Research Board for financial support of this research.

\section{LITERATURE CITED}

1. Adaskaveg, J. E., Förster, H., Driever, G., and Crisosto, C. 2007. Update on Mentor 45WP-a "new tool" for postharvest management of sour rot of stone fruit in the 2007 season. Pages 1-4 in: Central Valley Postharvest Newsletter. Online publication. http://www2.uckac.edu/postharv/newCVPN.htm

2. Agapow, P. M., and Burt, A. 2001. Indices of multilocus disequilibrium. Mol. Ecol. Notes 1:101-102.

3. Anderson, J. B., and Kohn, L. M. 1995. Clonality in soilborne plantpathogenic fungi. Annu. Rev. Phytopathol. 33:369-391.

4. Atallah, Z., K., Maruthachalam, K., du Toit, L., Koike, S. T., Davis, R. M., Klosterman, S. J., Hayes, R. J., and Subbarao, K. V. 2011. Population analyses of the vascular plant pathogen Verticillium dahliae detect recombination and transcontinental gene flow. Fungal Genet. Biol. 47:416-422.

5. Brown, G. E. 1979. Biology and control of Geotrichum candidum the cause of citrus sour rot. Proc. Fla. State Hortic. Soc. 92:186-189.

6. Burt, A., Carter, D. A., Koenig, G. L., White, T. J., and Taylor, J. W. 1996. Molecular markers reveal cryptic sex in the human pathogen Coccidiodes immitis. Proc. Nat. Acad. Sci. USA 93:770-773.

7. Butler, E. E. 1960. Pathogenicity and taxonomy of Geotrichum candidum. Phytopathology 50:665-672.

8. Butler, E. E., and Eckert, J. W. 1962. Taxonomy and physiological properties of fungus causing sour rot of citrus fruit. Phytopathology 52:1-5.

9. Butler, E. E., Fogle, D., and Miranda, M. 1988. Galactomyces citriaurantii a newly found teleomorph of Geotrichum citri-aurantii the cause of sour rot of citrus fruit. Mycotaxon 33:197-212.
10. Butler, E. E., and Petersen, L. J. 1972. Endomyces geotrichum a perfect state of Geotrichum candidum. Mycologia 64:365-374.

11. Butler, E. E., Webster, R. K., and Eckert, J. W. 1965. Taxonomy, pathogenicity, and physiological properties of the fungus causing sour rot of citrus. Phytopathology 55:1262-1268.

12. Chenna, R., Sugawara, H., Koike, T., Lopez, R., Gibson, T. J, Higgins, D. G., and Thompson, J. D. 2003. Multiple sequence alignment with the Clustal series of programs. Nucleic Acids Res. 31:3497-3500.

13. Dale, A. L., Lewis, K. J., and Murray, B. W. 2011. Sexual reproduction and gene flow in the pine pathogen Dothistroma septosporum in British Columbia. Phytopathology 101:68-76.

14. Davis, L. L., and Baudoin, A. B. A. M. 1986. Effect of osmotic potential on Geotrichum candidum growth, polygalacturonase production and polygalacturonase action. Physiol. Mol. Plant Pathol. 28:53-60.

15. Douhan, G. W., Peever, T. L., and Murray, T. D. 2002. Multilocus population structure of Tapesia yallundae in Washington State. Mol. Ecol. 11:2229-2239.

16. Eckert, J. W., and Eaks, I. L. 1989. Postharvest disorders and diseases of citrus fruits. Pages 179-260 in: The Citrus Industry: Volume V. W. Reuther, C. E. Calavan, and G. E. Carmen, eds. University of California, Division of Agriculture and Natural Resources, Oakland.

17. Ehrich, D. 2006. AFLPdat: A collection of R functions for convenient handling of AFLP data. Mol. Ecol. Notes 6:603-604.

18. Glass, N. L., and Donaldson, G. C. 1995. Development of primer sets designed for use with the PCR to amplify conserved genes from filamentous ascomycetes. Appl. Environ. Microbiol. 61:1323-1330.

19. Hershenhorn, J., Dori, S., and Barash, I. 1992. Association of Geotrichum citri-aurantii with citrus groves in Israel. Phytoparasitica 20:31-36.

20. Larkin et al. 2007. http://www.ebi.ac.uk/Tools/msa/clustalw2. European Bioinformatics Institute.

21. McDonald, B. A., and Linde, C. 2002. Pathogen population genetics, evolutionary potential and durable resistance. Annu. Rev. Phytopathol. 40:349-379.

22. Milgroom, M. G. 1996. Recombination and the multilocus structure of fungal populations. Annu. Rev. Phytopathol. 34:457-477.

23. Nakamura, M., Suprapta, D. N., and Iwai, H. 2008. Differentiation of pathogenic and nonpathogenic isolates of Geotrichum candidum sensu Suprapta et al. (1995) on citrus fruit based on PCR-RFLP analysis of rDNA ITS and PCR using specific primers designed in polygalacturonase genes. Mycoscience. 49:155-158.

24. Nakamura, M., Suprapta, D. N., Iwai, H., and Arai, K. 2001. Comparison of endo-polygalacturonase activities of citrus and non-citrus races of Geotrichum candidum, and cloning and expression of the corresponding genes. Mol. Plant Pathol. 2:265-274.

25. Page, R. D. M. 1996. TREEVIEW: An application to display phylogenetic trees on personal computers. Comput. Appl. Biosci. 12:357-358.

26. Peever, T. L., and Milgroom, M. G. 1994. Genetic structure of Pyreno- 
phora teres populations determined with random amplified polymorphic DNA markers. Can. J. Bot. 72:915-923.

27. Rozen, S., and Skaletsky, H. J. 2000. Primer3 on the WWW for general users and for biologist programmers. Pages 365-386 in: Bioinformatics Methods and Protocols: Methods in Molecular Biology. S. Krawetz, and S. Misener, eds. Humana Press, Totowa, NJ.

28. Smith, C. O. 1917. Sour rot of lemon in California. Phytopathology 7:37-41

29. Snowdon, A. 1990. A Colour Atlas of Post-Harvest Diseases and Disorders of Fruits \& Vegetables. Vol. 1: General Introduction \& Fruits. Wolfe Scientific, Ltd., London.

30. Stoddart J. A., and Taylor, J. F. 1988. Genotypic diversity: Estimation and prediction in samples. Genetics 118:705-711.

31. Suprapta, D. N., Arai, K., and Iwai, H. 1995. Distribution of Geotrichum candidum citrus race in citrus groves and non-citrus fields in Japan. Mycoscience 36:277-282.

32. Suprapta, D. N., Arai, K., and Iwai, H. 1996. Parasitic specialization of Geotrichum candidum citrus race. Mycoscience 37:105-107.

33. Suprapta, D. N., Arai, K., and Iwai, H. 1996. Some physiological properties of citrus and non-citrus races of Geotrichum candidum isolated from soil in Japan. Mycoscience 37:401-407.
34. Swofford, D. L. 2002. PAUP. Phylogenetic Analysis Using Parsimony and Other Methods, Version 4.0b10. Sinauer Associates, Inc., Sunderland, MA.

35. Taylor, J. W., Geiser, D. M., Burt, A., and Koufopanou, V. 1999. The evolutionary biology and population genetics underlying fungal strain typing. Clin. Microbiol. Rev. 12:126-146.

36. Taylor, J. W., Jacobson, D. J., and Fisher, M. C. 1999. The evolution of asexual fungi: Reproduction, speciation and classification. Annu. Rev. Phytopathol. 37:197-246.

37. Vos, P., Hogers, R., Bleeker, M., Reijans, M., Lee, T., Van de Hornes, M., Frijters, A., Pot, J., Peleman, J., Kuiper, M., and Zabeau, M. 1995. AFLP: A new technique for DNA fingerprinting. Nucleic Acids Res. 23:44074414.

38. Weir, B. S., and Cockerham, C. C. 1984. Estimating F-statistics for the analysis of populations. Evolution 38:1358-1370.

39. Zhan, J., and McDonald, B. A., 2005. Analytical and experimental methods for estimating population genetic structure of fungi. Pages 241263. in: The Fungal Community, Its Organization and Role in the Ecosystem. Third Edition. J. Dighton, J. F. White, and P. Oudemans, eds. CRC Press, Boca Raton, FL. 